\title{
De la tierra venimos y a los Apus volvemos: una interpretación del yacimiento arqueológico Pacajes-Inka de Mazocruz (La Paz, Bolivia)
}

Javier Armando Méncias Bedoya

Recibido: 21-abr-20

Aprobado: 20 -oct-20

doi: $10.46476 /$ ra.v1i2.38

\section{Resumen}

El presente artículo exhibe una serie de disquisiciones, basadas en la etnohistoria, análisis de Sistemas de Información Geográfica y observaciones etnoarqueológicas preliminares, relacionadas al yacimiento arqueológico de Mazocruz. El objetivo es acercarse a una interpretación sobre el porqué del uso del yacimiento como necrópolis, con cámaras mortuorias subterráneas, durante los períodos Intermedio Tardío - final- y Horizonte Tardío (Inka), en clara divergencia con el patrón funerario que caracteriza a estos, donde las torres funerarias o chullpares son el elemento de uso más común en el altiplano sur-central.

Palabras Clave: Sistemas de Información Geográfica, etnoarqueología, Intermedio Tardío, Horizonte Tardío, Altiplano Sur-Central. 


\section{Abstract}

This paper contains a series of disquisitions based on ethnohistory, Geographic Information Systems analysis, and preliminary ethnoarchaeological observations on the Mazocruz archaeological site. The intention here is to begin to develop an interpretation of the use of this site as a necropolis, with subterranean mortuary chambers, towards the end of the Late Intermediate and the Late Horizon (Inka) periods, a use that clearly diverges from the funerary pattern typical of said periods, in which funerary towers, or chullpares, were the most commonly used element in the south-central Altiplano.

Keywords: Geographic Information Systems, ethnoarchaeology, Late Intermediate, Late Horizon, south-central Altiplano.

\section{Resumo}

Este artigo apresenta algumas disquisições, baseadas em etno-história, análise de Sistemas de Informações Geográficas e observações etnoarqueológicas preliminares, relacionadas ao sítio arqueológico de Mazocruz, com o objetivo de abordar uma interpretação do uso deste sito como uma necrópole, com câmaras mortuárias subterrâneas, no final do período intermediário tardio e do horizonte tardio, em clara divergência com o padrão funerário que os caracteriza, onde torres funerárias ou chullpares são o elemento de "uso mais comum" no Altiplano Centro-Sul.

Palavraschave: Sistemas de Informação Geográfica, Etnoarqueologia, Intermediário Tardio, Horizonte Tardio, Altiplano Centro-Sul. 


\section{Introducción ${ }^{1}$}

Luego del relevante hallazgo de una serie de cámaras mortuorias en el yacimiento arqueológico de Mazocruz ${ }^{2}$, que fuesen investigadas y rescatadas por SCIENTIA CC (Sagárnaga (Comp.) 2019), se consideró necesario, debido a las llamativas particularidades que exhibe el hallazgo y al trabajo netamente descriptivo que se ha tejido alrededor del mismo, realizar un ejercicio interpretativo delas probables razones que habrían llevado a las poblaciones Pacajes-Inka - desde el Intermedio Tardío hacia el Horizonte Tardío (ca. 1470-1540 d.C.) - a emplear el área como necrópolis. El interés surge porque estas construcciones presentan una sugestiva divergencia con el reconocido patrón de enterramiento en torres funerarias o chullpares $^{3} \mathrm{y}$, en menor medida, los enterramientos en cuevas y grietas rocosas, ${ }^{4}$ que caracterizan este rango temporal de la época prehispánica en los Andes sur-centrales.

El Altiplano paceño, entendido como la región geográfica en la que se halla el yacimiento y que ocupa $30.424 \mathrm{~km} 2$ (Colque, 2009, p.24), se caracteriza por presentar una alta densidad de sitios, complejos y yacimientos arqueológicos, los cuales representan toda la secuencia ocupacional reconocida en la macrorregión, desde el Arcaico (10.000 A.P.) hasta el Horizonte Tardío. Específicamente, para el rango temporal que nos ocupa, se ha identificado más de 250 sitios, complejos y yacimientos arqueológicos, de los que más del $45 \%$ poseen indicadores funerarios. Del total de sitios con evidencia funeraria en el altiplano de La Paz, cerca del 50\% posee filiación Pacajes o Pacajes-Inka y de este total, un significativo 80,6\% se presenta en la modalidad de torre funeraria o chullpar, por lo que es aceptable asumir que este constituía el patrón de inhumación preferido en el período.

Una revisión de la información que la consultora SCIENTIA ha publicado al respecto (cf.Ibíd.), señala que, de acuerdo con información de los investigadores involucrados en el hallazgo, al menos tres cámaras funerarias, a una profundidad de entre 84 y $207 \mathrm{~cm}$ debajo de la superficie moderna, habrían sido abiertas, exhumando su

1. A mi querido amigo y colega Esdras Calderón Bernal (con quién compartí algunas de las ideas aquí vertidas mientras visitamos el yacimiento de Mazocruz, allí por el año 2017, en la primera campaña de campo que se realizara en el yacimiento). Recordando ello, también deseo agradecer a Jédu Sagárnaga la posibilidad de conocer el yacimiento, para su evaluación inicial y para perfilar las interpretaciones espaciales, herramientas y propuestas que llevarían al hallazgo definitivo. A la colega y entrañable amiga Liz Gonzales Ruiz, por su dedicada revisión de este escrito y las invaluables observaciones y adiciones brindadas, que respeté fielmente por su precisión y valor. Finalmente, a Armando Méncias por su constante apoyo y presencia, y a Mariana -musa y compañera- por la eterna comprensión.

2. Denominativo local para una prominencia geológica que se halla constituida por rocas puzolánicas/ volcánicas, en actual extracción por parte de la empresa ESMICAL S.A.

3. Como se denominan en el Altiplano Sur-Central. Para el patrón referido, a guisa de ejemplo, véase Bouysse-Cassagne (1987); Gil García (2001, 2002); Kesseli y Pärssinen (2005); Rozas (2012); Sagárnaga (2006).

4. Véase, por ejemplo, Dillehay (ed., 2005); Kaulicke (1997, 2018); Tantaleán (2006). 
contenido. La principal de ellas fue la codificada como R103, que se caracterizaba por presentar una «chimenea» de acceso de $80 \mathrm{~cm}$ de diámetro y $270 \mathrm{~cm}$ de longitud, con dos cámaras funerarias que habrían albergado restos humanos, depositados en fardos junto con su correspondiente ajuar (cerámico, lítico, orgánico, principalmente objetos de madera y textiles, además de objetos metálicos), que ascenderían a un total estimado de 108 individuos depositados en tres «niveles» sucesivos, supuesto debido al pésimo estado de conservación y casi completa desaparición de los restos humanos. Los análisis por especialidad, realizados por los investigadores, nos presentan un rico ajuar con materiales claramente relacionados a grupos Pacajes e Inkas locales, de donde procede su filiación cronológica. Sin embargo, se echa mucho de menos, en estos sucintos escritos, un ejercicio interpretativo del contexto hallado.

Hasta el momento, en Bolivia se desconocía de cámaras funerarias labradas en roca, correspondientes al período en cuestión, y la literatura arqueológica de países vecinos muestra una ausencia casi total de conocimiento en torno a este tipo de hallazgos. ${ }^{5}$ Esto confirma que este tipo de arquitectura rupestre constituye una anomalía en el rango temporal y desarrollos culturales involucrados. ${ }^{6}$ Sin embargo, una pequeña pesquisa en el vocabulario de Bertonio (1984 [1612]), documento lingüístico Colonial más cercano a los grupos aymara de la región (entre los que consideramos a los Pacajes), nos presenta una serie de definiciones útiles que nos llevan a afirmar la existencia de conceptos y probables prácticas, relacionadas con el enterramiento en cámaras subterráneas:

- En la página 101 de la primera parte define:

- Boueda para enterrar: Puticallca.

- En la página 217:

- Enterrar muertos. Amaya imaña.

- En la página 430:

- Sepultura debaxo dela tierra cauada no mas: Imaui.

- Sepultura como una caxa de muchas piedras para enterrar la gente principal debaxo dela tierra: Callca.

- En la página 34 de la segunda parte:

- Callca: Sepultura de piedras debaxo de tierra para los principales.

- En la página 282 (Phutti):

- Cala Phutti: Sepulcro.

- Cala callca: La bouedilla donde fe enterrauan los indios, y oy dia lo vfan.

Otra fuente lingüística de gran valor, es el vocabulario quechua del jesuita Diego González Holguín (1952 [1608]), donde se exhibe:

5. Exceptuando el caso del sitio de Ñawpa Iglesia/Choqella (ver Kosiba, 2015).

6. A diferencia de otros yacimientos, como los identificados en Perú -ej. La Galgada, Kuntur Wasi, Chicama- para los períodos Arcaico Final, Formativo y Formativo Tardío, u otros, más tardíos, de tradición Mochica (cf. Donnan, 1995; Kaulicke, 1994; Larco, 1941; Onuki, 1995, 1997). 
- En la página 173, del primer libro:

- Mullpascca aya, pintuna huan. El cuerpo muerto ya corrompido y su mortaja.

- En la página 188:

- Pamppani ayacta o allpahuanpacani. Enterrar muertos.

- En la página 282:

- Carcomida madera podrida, o cosa que esta al agua o en lugar humedo o debaxo de tierra. mullpascca o el cuerpo muerto o su mortaja.

- En la página 317, del libro segundo:

- Enterramiento. Ayappampaynin.

En ese sentido, queda claro que la modalidad de entierro subterráneo existía en el concepto indígena de la época en la que se sitúa el hallazgo ${ }^{7}$ y podemos pasar a desarrollar otras particularidades que acompañan el macrocontexto del yacimiento.

\section{El suelo en la cosmovisión andina}

Según los conceptos sobre la cosmovisión, tratamos con «la elaboración humana que recupera las maneras de ver, sentir y percibir la totalidad de la realidad, esto es los seres humanos, el conjunto de la naturaleza y el cosmos» (Centro de Culturas Originarias Kawsay, 2005, p.14); asimismo, «es la forma en que una población percibe el mundo o el cosmos. La cosmovisión incluye las relaciones que se asumen y se llevan a cabo entre el mundo espiritual, el mundo natural y el mundo social. Describe el rol de los poderes sobrenaturales, la forma en que los procesos naturales se llevan a cabo y la relación entre la humanidad y la naturaleza» (Haverkort, 2001, p.12). En ese sentido, se comprende la existencia de una fuerte corriente de investigación en el continente americano, desde el inicio de las investigaciones antropológicas y arqueológicas, la cual intenta interpretar y delinear aquellos principios inherentes a la cosmovisión de los pueblos andinos y su relacionamiento con los elementos que conforman su medio natural y simbólico.

Kusch (1970) ya señalaba, en el caso aymara, que detrás de su pensamiento subyace un principio «seminal» (bajo el modelo del desarrollo biológico), en el que acontecimientos y cosas se generan a partir de la fuerza vital del universo encarnado en la Pachamama. Esta permite que la vida crezca, florezca, dé fruto y se multiplique cuando existen condiciones favorables, bajo dos elementos clave: el cariño y la comprensión. El primero resulta de la relación personal entre el sujeto y su objeto de trabajo, reclama dedicación y afecto, y se refleja en la convivencia entre el sujeto y su suelo. El segundo, por otro lado, se refleja en la capacidad del sujeto de observar dedicada y acuciosamente su entorno, sintiendo, a partir de

7. Como uno de los principales patrones funerarios, cuya raigambre se encuentra en el Período Formativo (ca. 1500 a.C.-400 d.C. en la región que nos ocupa), y llega a su mayor intensidad durante el Horizonte Medio (ca. 400-1100 d.C.). 
los fenómenos de la naturaleza, la vida íntima de todo, entendiendo su lenguaje y sintonizándose con él.

Como puntualiza Jan van Kessel:

La mitología aymara no conoce un Dios creador, trascendente y ajeno al mundo, ni una creación o confección del mundo. La tierra misma es divina y eterna. Pachamama, la Diosa principal de los aymaras, no confecciona flora, fauna y humanos: todos estos «nacen» de ella. La divinidad es inmanente en el mundo, está dentro del mundo y se identifica plenamente con la tierra. La relación entre Pachamama y sus criaturas es la de una madre a sus hijos y de éstos hacia ella: cargada de afecto (1990, pp.161-162).

Para acercarnos un poco a los conceptos que reafirman la importancia del suelo, dentro del concepto que se cree emana del pensamiento andino en el pasado, podemos recurrir a algunos estudios etnográficos y etnológicos, hoy en día bastante desarrollados desde disciplinas auxiliares a la Arqueología, partiendo del principio que propone que la «Religión Popular Nativa» no sufrió grandes cambios ${ }^{8}$ en su núcleo significativo primordial, a pesar del proceso histórico colonial y sus pretensiones evangelizadoras. ${ }^{9}$

En estos estudios se considera que su cosmología se organiza alrededor de tres principios: la dualidad, la complementariedad y la reciprocidad (Harris, 1978; Mamani, 1989). Estos principios se encuentran presentes, interrelacionados y activos en una particular clasificación del universo, en tres espacios: el alax pacha (mundo ultraterreno, con espíritus celestes y seres sobrenaturales), el aka pacha (nuestro mundo, con espíritus tutelares) y el manqha pacha (mundo inferior, con espíritus «maléficos» que viven al interior de la tierra). ${ }^{10}$

Un estudio basado en las crónicas peruanas de los siglos XVI y XVII ha sido preciso al perfilar, desde la óptica Inka, la percepción de la Pachamama. Sobre la base de la información brindada por varios cronistas, a partir del último tercio del siglo XVI, Daniela di Salvia (2013) hace visible la existencia de un culto a la Tierra (con el apelativo que se conoce en la actualidad), en el que la connotación de «madre» caracteriza su rol en la vida diaria de la sociedad andina prehispánica. Igualmente, señala que su representación figurativa tendría como principal soporte el barro, aspecto de doble afirmación (siendo la materia prima proveniente del ente al que

8. El concepto se desarrolla en Querejazu (1996), también se trata como Religiosidad Popular Andina (Querejazu, 1994).

9. Múltiples investigaciones recientes consideran este fenómeno y vienen aceptándolo cada vez con más convicción (cf. Siracusano 2005; Berrojalbiz (ed.) 2015).

10. Puede hallarse una descripción bastante completa en la obra de Narciso Valencia (1998), denominada La Pachamama: Revelación del Dios creador. 
representa), que ha sido verificado, por ejemplo, en el caso de los colores (Burucúa, Siracusano y Jáuregui, 2000; Siracusano, 2005). A partir del análisis de todas sus fuentes, el estudio concluye con tres consideraciones; en primer lugar, que «el culto a la Tierra tenía una relevancia fundamental dentro del conjunto de prácticas y rituales de culto autóctonos (...)»; en segundo lugar, «el imaginario colectivo andino tenía de la Pachamama una precisa concepción simbólico-icónica, primariamente identificable con la tierra en sí (...)» y, finalmente, que «existía todo un acervo de invocaciones y dedicaciones dirigidas específicamente a la Pachamama (...)» (di Salvia, 2013, p.107), por lo tanto se puede suponer que esta divinidad gozaba de importancia capital en el panteón Inka, y en el ciclo ritual que ordenaba el mismo.

La experiencia religiosa andina, que es considerada un axioma en la construcción de su cosmovisión, constituye el nodo central de la vida y sus ciclos anuales en el altiplano. A decir de Narciso Valencia, por ejemplo, «el aymara expresa lo sagrado por medio de mitos, conceptos, acciones rituales y símbolos que ha ideado y organizado desde hace miles de años, y los expresa de manera personal, familiar y comunitaria» (Valencia, 1999, p. 33). Este bagaje conceptual y ritual, presente también en grupos quechuas, se halla ensamblado a una de sus principales deidades: la Madre Tierra; ${ }^{11}$ sin embargo, la característica deífica de esta sitúa sus actuaciones tanto en el ámbito del orden como en el del caos y conflicto, obligando al ser humano a buscar protección en seres/espíritus tutelares que intercedan por el restablecimiento del equilibrio. Entre ellos podemos mencionar a los Achachilas, de los cuales algunos son Apu o Abuelo (encarnados en las montañas), y los Uywiris. ${ }^{12}$

Aunque son pocas las investigaciones al respecto, algunos autores ( $c f$. Schobinger, 1999; Sánchez, 2006; Gil y Fernández, 2008; Cruz, 2009; Ceruti y Reinhard, 2010; Reinhard, 2012; Cruz, Crubézy y Gérard, 2013) proponen que todos los nevados que constituyen la cadena montañosa Andina son Apus con distintos grados de importancia, por lo que, considerando la región del departamento de La Paz, tendríamos los siguientes (de menor a mayor en m s. n. m.): Mururata (5.871), Chaupi Orco (6.044), Chachacomani (6.074), Huayna Potosí (6.088), Chearoco (6.127), Illampu (6.368), Ancohuma (6.427) e Illimani (6.438).

A los conceptos de Achachila y Uywiri les acompaña, invariablemente, el concepto de Wak'a. Vale la pena recordar que, en el mundo andino sur-central, «una huaca es una fuerza sobrenatural que se encarna en cualquier objeto o lugar sagrado. Cada cerro, río, roca y cada manifestación singular de la naturaleza u objetos

11. Actualmente llamada Pachamama.

12. Los Achachilas velan por la vida de los pobladores de una región (Apu o Jach’a Achachila), comunidad o sector (Jisc'a Achachila), mientras que los Uywiris protegen los bienes, los productos y el hogar. Los atributos de ambos provienen de la propia Pachamama (quien es su causa y fundamento). (Valencia, 1998; Steele y Allen, 2004). 
específicos, como templos y enterramientos, eran por sí mismos considerados sagrados» (Méncias, 2010, p. 321), por lo que su calidad de wak'a es intrínseca a su sacralidad y relevancia social, y se halla igualmente sujeta a una jerarquía relacionada con el culto a los ancestros (como cimiento primordial de la religión popular prehispánica) y su función en el espacio geográfico.

Mayores y recientes investigaciones se han enfocado en el carácter animístico, totémico, deífico y ontológico de las wak'as (Bray (ed.), 2015), dotando al concepto de una profundidad que clarifica algunas de las razones por las que no cualquier río, roca o árbol, por considerar algunos elementos naturales relevantes, son wak'a.

Es de especial interés el comprender que, sin embargo, los restos humanos inhumados entre el 1100 y el 1530 d.C., aproximadamente, son considerados un importante componente en el proceso de «sacralización» del espacio (Kosiba, 2015; Chase, 2015), por lo que su presencia, para la mayoría de los autores relacionados con la materia, constituye un relevante elemento de juicio a la hora de determinar la existencia de una wak'a.

\section{Particularidades vulcanológicas y contexto geográfico}

No cabe duda que los volcanes, siendo prominencias geográficas llamativas, ya inactivos desde hace decenas de miles de años, constituyeran waḱas; por lo tanto, tampoco debería llamar la atención que muchos de ellos estuvieran relacionados con los mitos de origen de muchas etnias prehispánicas, al interior de la cosmovisión de los pueblos andinos. Como ejemplo hallamos la contestación de Joan de Ulloa, corregidor de Arequipa en 1586, quien señaló que los autodenominados Collaguas, ${ }^{13}$ de acuerdo con sus propias palabras, habrían salido por o desde dentro del cerro nevado Collaguata, que identifica —atinadamente— con un volcán apagado. (Ulloa 1889 [1583]).

Otro aspecto prominente, temido y reconocido por los pobladores de los Andes, es el poder destructivo en la explosión de los volcanes. Uno de los ejemplos más dramáticos ha sido recopilado mediante la búsqueda de sucinta información de los cronistas de la época, quienes refieren la explosión del volcán Huayna Putina hacia febrero del año 1600. Este evento, tratado desde múltiples ópticas investigativas ( $c f$. Bouysse-Cassagne y Bouysse, 1984; 1988, Medinacelli (coord.), 2012; Méncias, 2018; Gentile, 2018), marcó, sin lugar a dudas, a las poblaciones locales, a más de servir a los españoles como un ejemplo evangelizador y parámetro comparativo entre estas entradas al inframundo y la actividad idolátrica local. Siendo uno de los ejemplos más cercanos, y conociendo sus implicancias ambientales y sociales (como el traslado de poblaciones completas, y la fundación de nuevos pueblos), no se puede dejar de pensar en las implicancias

13. Una etnia que poblaba la provincia del mismo nombre. 
simbólico-religiosas que este tipo de acontecimientos tendría en la percepción de los pobladores locales.

En la época Inka, por ejemplo, el temor a la ira de los volcanes sirvió como detonante para una de las prácticas de ofrenda más llamativas de las que tenemos evidencia: la Capacocha. Los niños ofrenda, enterrados muchas veces en regiones muy alejadas de sus sitios de origen, tenían por objetivo «estrechar lazos entre el Cusco y los dioses de aquellos lugares, o (...) aplacar las iras de los apus y de la Pachamama, madre de todos los mortales» (Martín, 2009, p.190). Esta práctica, descrita de forma muy detallada solamente por el cronista Juan de Betanzos (2004 [1551-1557]), posee algunos de sus mayores y mejor conservados indicadores, en los enterramientos rituales de niños, sucedidos en las cimas de los volcanes nevados de la cordillera, como el Ampato o el Llullaillaco, en las regiones centro-sur y sur Andinas.

Dejando lo anterior para más adelante en el texto, recordemos que el yacimiento arqueológico de Mazocruz también se constituye en un yacimiento geológico de puzolanas de origen volcánico que se presenta, en términos topográficos, como una eminencia de tipo cerro, loma o colina (de acuerdo con la clasificación de Valencia 1987), que ocupa aproximadamente 40 hectáreas de extensión y se encuentra circundada por planicies semiondulantes de característica inundable (Figura 1), y que corren de noroeste a sudeste, paralelas a la línea cordillerana (que dista menos de $40 \mathrm{~km}$, en el espectro que cubre la vista desde el norte al este).

Las puzolanas son materiales silíceos o aluminio-silíceos (es decir, contienen sílice y aluminio, además de hierro, en forma de óxidos: $\mathrm{SiO} 2, \mathrm{Al} 2 \mathrm{O} 3, \mathrm{Fe} 2 \mathrm{O} 3),{ }^{14}$ empleados en la producción de cemento. En este caso, tratamos con un yacimiento de puzolanas naturales de origen mineral, que se originaron debido a una transformación del polvo y cenizas volcánicas por un proceso de meteorización. Este proceso, en el caso de todos los yacimientos puzolánicos conocidos, convierte el polvo y cenizas en tobas con distintos grados de consolidación y compactación, pudiendo ser cristalinas, líticas o vítreas, dependiendo de su origen volcánico, como lo explica Salazar (2001).

Estos principios del origen de las puzolanas, consciente o inconscientemente conocidos por las poblaciones antiguas, las relacionan de forma directa e ineludible con las montañas y nevados que se hallan en la región de la cordillera de los Andes, y que alguna vez fueron volcanes activos, constituyéndose, por tanto, en los principales elementos de correlación con su origen telúrico y la subsecuente significancia cosmogónica que emana de él (un fenómeno que se podría denominar como «cosmogénesis cultural»).

14. Entre los que sílice es el más importante de los óxidos y no debe bajar de $40 \%$ del total, si se pretende su uso en fabricación de cemento. 
Figura 1. Mapa de ubicación del yacimiento de Mazocruz (arriba) con vista 3D del entorno (abajo).

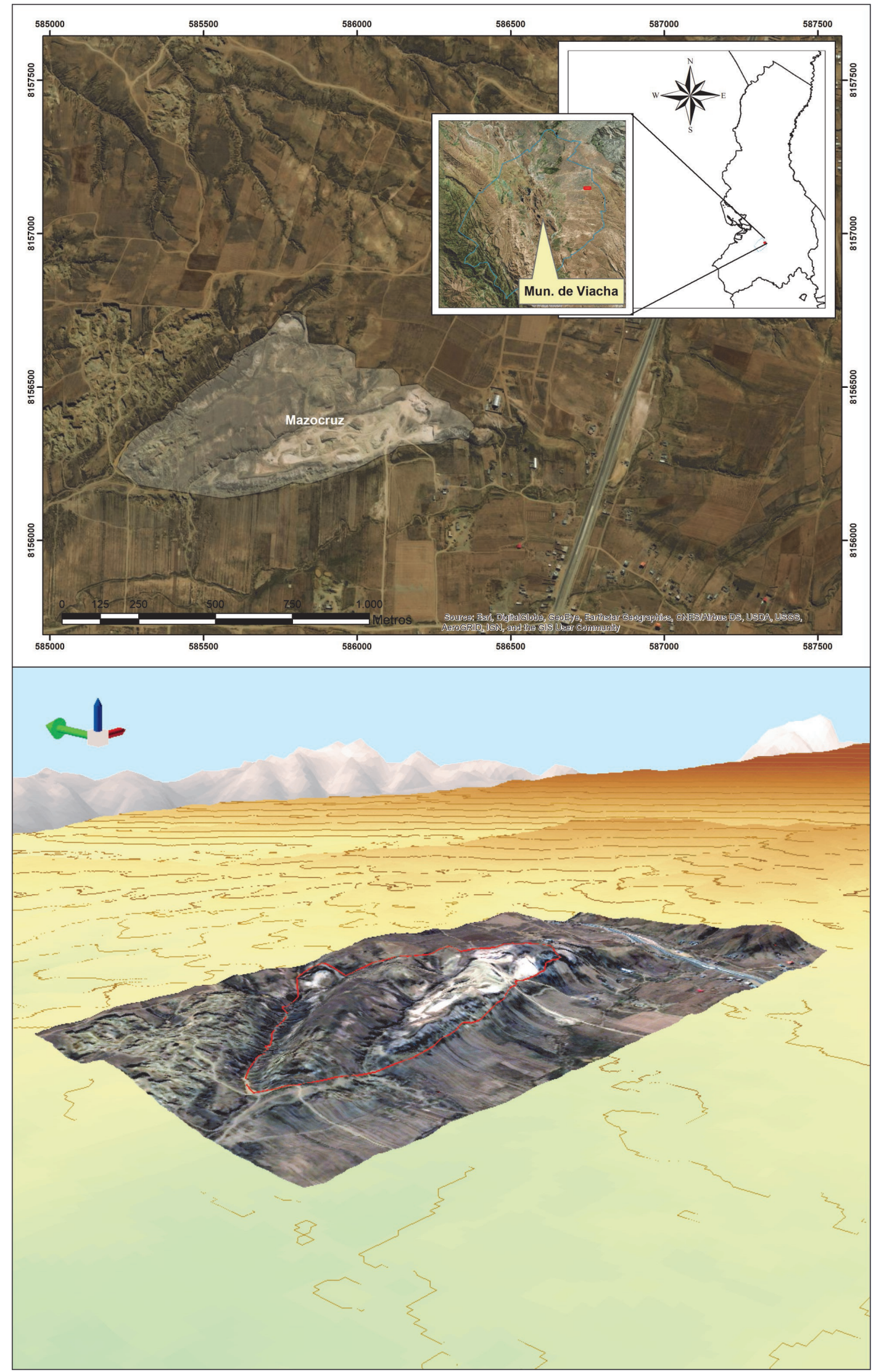

Elaboración propia 


\section{Mazocruz y su entorno visual-paisajístico}

Particularmente, en la investigación arqueológica, el concepto de paisaje - aunque relativamente nuevo - cobra una vigencia y uso cada vez mayor en la ciencia; en el mundo casi ha sustituido al concepto de medio ambiente y, actualmente, se puede asegurar que se ha convertido en parte del acervo cultural de algunas sociedades. Su aparición en la Arqueología - como una disciplina, denominada Arqueología del Paisaje- nace de su confluencia con las ciencias ecológicas y paleoambientales. Sin embargo, no existe un uso homogéneo de la expresión ni de los métodos que se aplican a esta joven disciplina. (González, 2006)

En general, se acepta que la Arqueología del Paisaje se ocupa de la reconstrucción o recreación de los paisajes en su evolución desde la presencia del ser humano en la unidad de análisis escogida. Por lo tanto, el paisaje arqueológico posee una connotación antrópica relacionada, de alguna manera, a la medición del impacto de la especie humana en la historia del medio ambiente y la manera en la que esta historia se ha desarrollado en el tiempo (Bradford, 1957). Es decir, la forma en la que se pueden evidenciar los signos que expresan la presencia del ser humano en la esfera del medio natural, o cómo este medio ha sido antropizado (Leveau, 2005, pp.16-19), desde un trasfondo sistémico.

En el estudio de los sistemas hombre-medio ambiente se dan tres corrientes. La primera y más tradicional se centra en el concepto de paisaje cultural y analiza la interacción humana con el mundo físico a través de las huellas tangibles del hombre en la superficie de la tierra. La segunda, ecológica, se ocupa de los procesos de interacción entre el hombre y el medio ambiente, más que de su forma y contenido. La tercera se ocupa de la percepción del medio ambiente, de las «imágenes» que el hombre se hace de su entorno, como clave para desentrañar el tipo de las relaciones hombre-naturaleza, de acuerdo con English y Mayfield (eds., 1972, p. 2).

Entonces, partiendo del breve punteo enfocado en la cosmovisión y la concepción del suelo, entendemos que los espíritus tutelares estén poblando todo el paisaje andino, y su constante presencia, percibida de forma visual o relatada (desde un enfoque mítico), influya en el diario actuar del poblador altiplánico, así como en sus festividades o su ciclo agrícola, tanto en la vida como en la muerte. Con relación a ello, el entorno visual de Mazocruz, entendido como el horizonte que lo circunda, presenta una llamativa secuencia montañosa con el Huayna Potosí, el Mururata y el Illimani como los elementos geográficos más relevantes en un rango visual de $90^{\circ}$ del norte el este (Figura 2), siendo el Illimani el que más resalta a simple vista. 
Figura 2. Vista 3D del rango visual -ideal- Norte a Este de Mazocruz (con nevados resaltados).

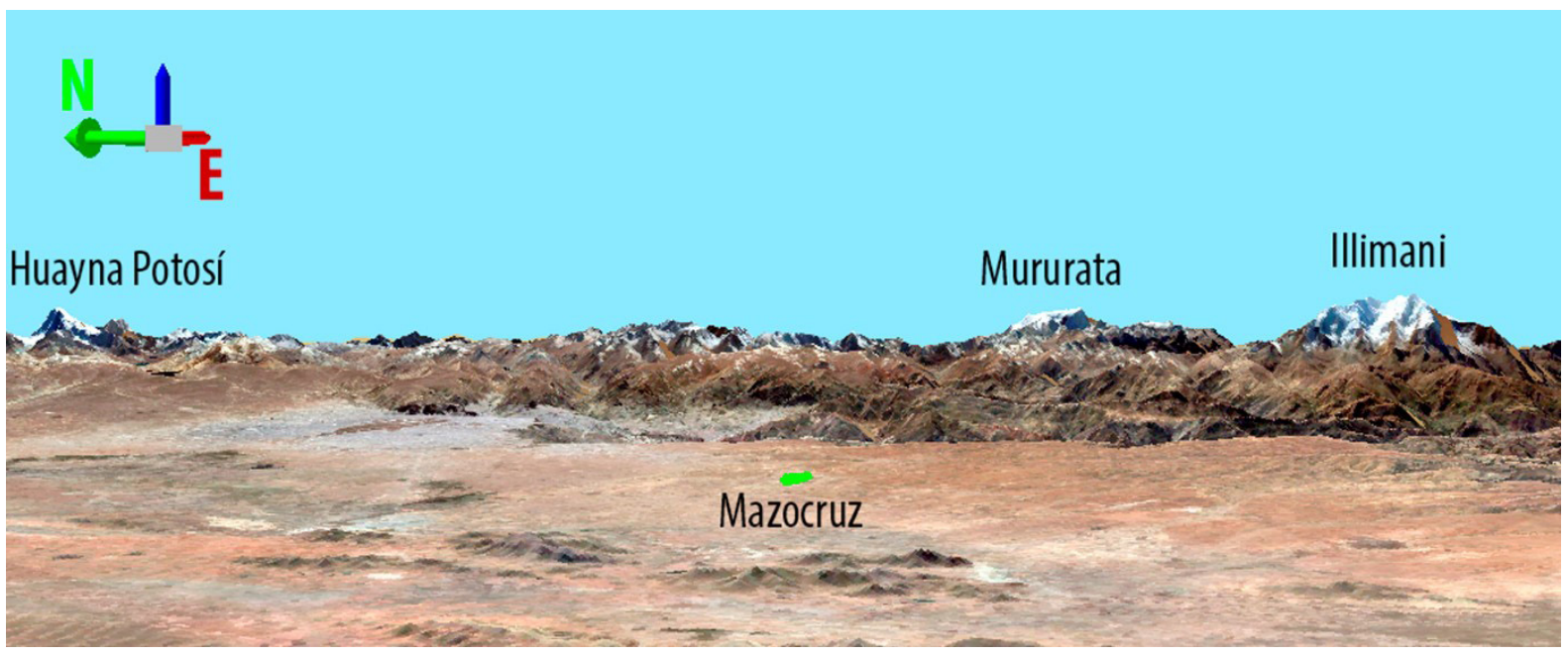

Elaboración propia

En orden de contrastar la visualización de horizonte, verificada en campo, con las posibilidades visuales hipotéticas, se decidió aplicar un cálculo de visibilidad mediante la aplicación de Sistemas de Información Geográfica -SIG- (Llobera, 2003), cuya utilidad radica en determinar, desde un punto de observación, qué zonas o superficies del terreno circundante son visibles (Tévar 1996). ${ }^{15}$ Para ello, se emplearon dos tipos de análisis: a) Análisis de Línea de Visión, que determina lo que es visible y lo que es oculto a lo largo de una línea desde el punto de observador (cámara funeraria) hasta el objetivo de observación (la montaña); b) Análisis de Cuenca Visual, que determina las ubicaciones visibles para un observador en todas las direcciones, para un rango determinado.

Los SIG son sistemas de información, diseñados para manejar una cantidad significativa de datos que contienen un correlacionamiento y ubicación geográficos, resultantes de coordenadas geográficas asignadas a ellos (Star y Estes, 1990), cuyo análisis y gestión es asistida por un computador. En el caso de la modelación de visibilidad, en la que priman las ideas de cuenca visual y línea de visibilidad, los arqueólogos se han enfocado en que si esta ha sido un factor de relevancia para las poblaciones del pasado al momento de preferir o elegir la ubicación específica de un sitio o monumento (Llobera, 2018), por lo que su aplicación, en el particular caso de Mazocruz, constituye un ejercicio obligatorio.

El análisis de Líneas de Visión fue practicado mediante la aplicación del complemento Military Tools for Arcmap, en su variedad radial. El análisis requirió

15. En nuestro caso, el punto de observador está constituido por la coordenada precisa de las cámaras funerarias masivas, mientas que el entorno es representado por un Modelo de Elevación Digital - DEM «ALOS PALSAR» de 12.5 metros de definición en píxel, y el rango de visibilidad máximo es de $50 \mathrm{Km}$. 
la definición de un punto de observador (situado en la coordenada media de las cámaras funerarias), una distancia (fijada en $55 \mathrm{~km}$ desde el punto) y un campo de visión (en nuestro caso de 0 a 90 grados) relacionado al norte, todo sobre un Modelo de Elevación Digital -DEM en inglés, para el que se eligió un ráster ALOS PALSAR (de 12,5 metros de valor de detalle por píxel). El gráfico resultante presenta dos colores: a) Rojo, representando no visibilidad; b) verde, representando visibilidad. A partir de lo anterior, se puede inferir que el mapa exhibe una visibilidad total de los picos en los nevados Mururata e Illimani (Figura 3).

Figura 3. Análisis del Radio de Visión a los principales nevados

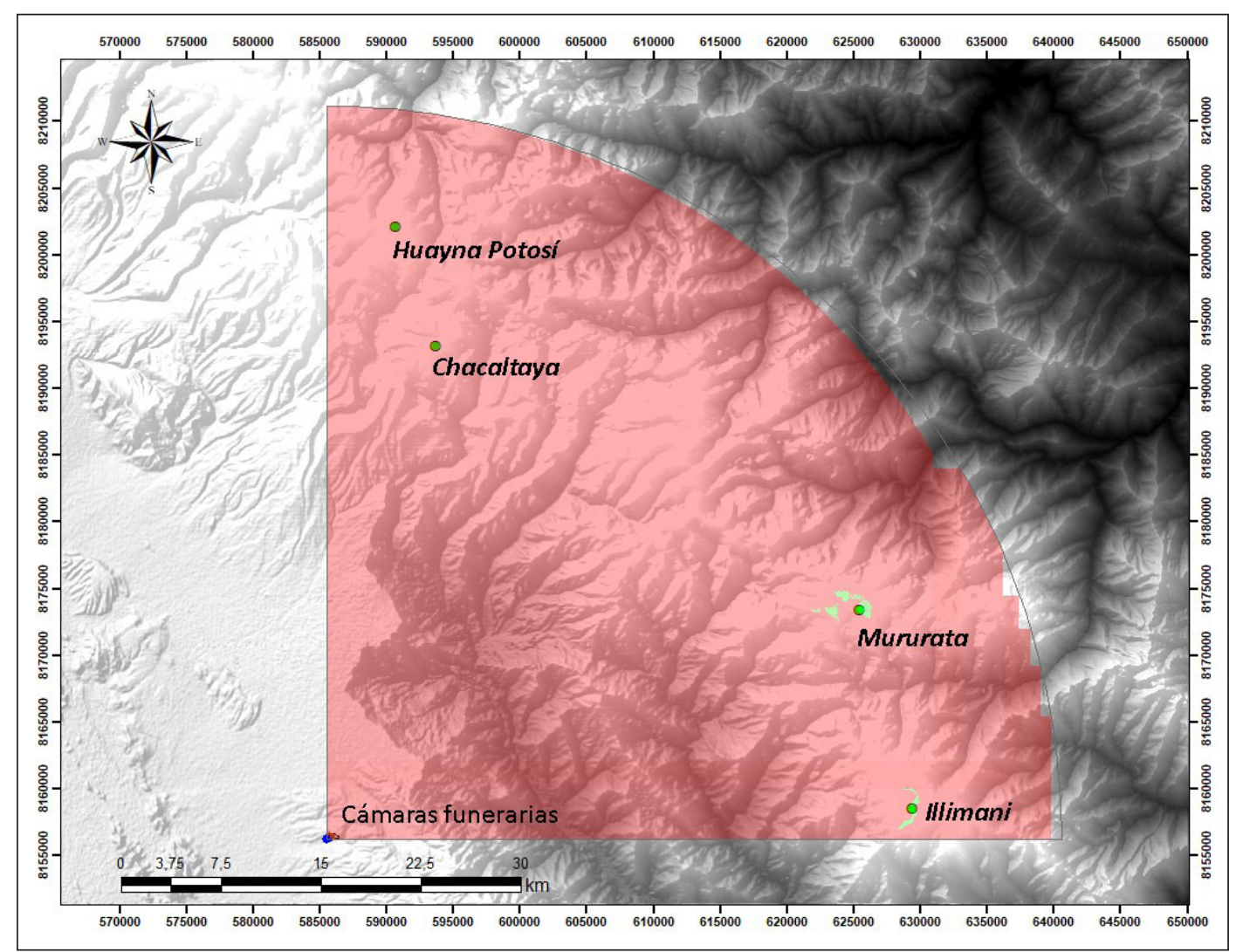

Elaboración propia

En cuanto al análisis de Cuenca Visual, se empleó una capa con todos los valores concernientes a los nevados, además del punto que representa las cámaras funerarias, con el objetivo de realizar un análisis de intervisibilidad. Para realizar el mismo, se emplean las herramientas Viewshed o Cuenca Visual, y Observer Points o Puntos de Observador, cruzando la capa de ráster DEM y la capa con los puntos georreferenciados. El resultado del análisis de ambos evacúa dos tipos de mapa: a) uno que muestra una clara visibilidad, representada por el color verde, de las principales quebradas de los nevados, los propios nevados y la planicie en la que se sitúa el yacimiento de Mazocruz y b) uno que refleja una relación de intervisibilidad clara, representada por las manchas rojizas, entre los nevados Illimani y Mururata ( $83 \%$ de los casos de observación en la cuenca), y entre estos 
y el área de cámaras funerarias (con el segundo porcentaje más significativo de la cuenca, Figura 4). Esta es una particularidad que no se presenta entre el área de cámaras funerarias y los demás nevados de la región.

Figura 4. Análisis de la Cuenca Visual relacionada a los principales nevados

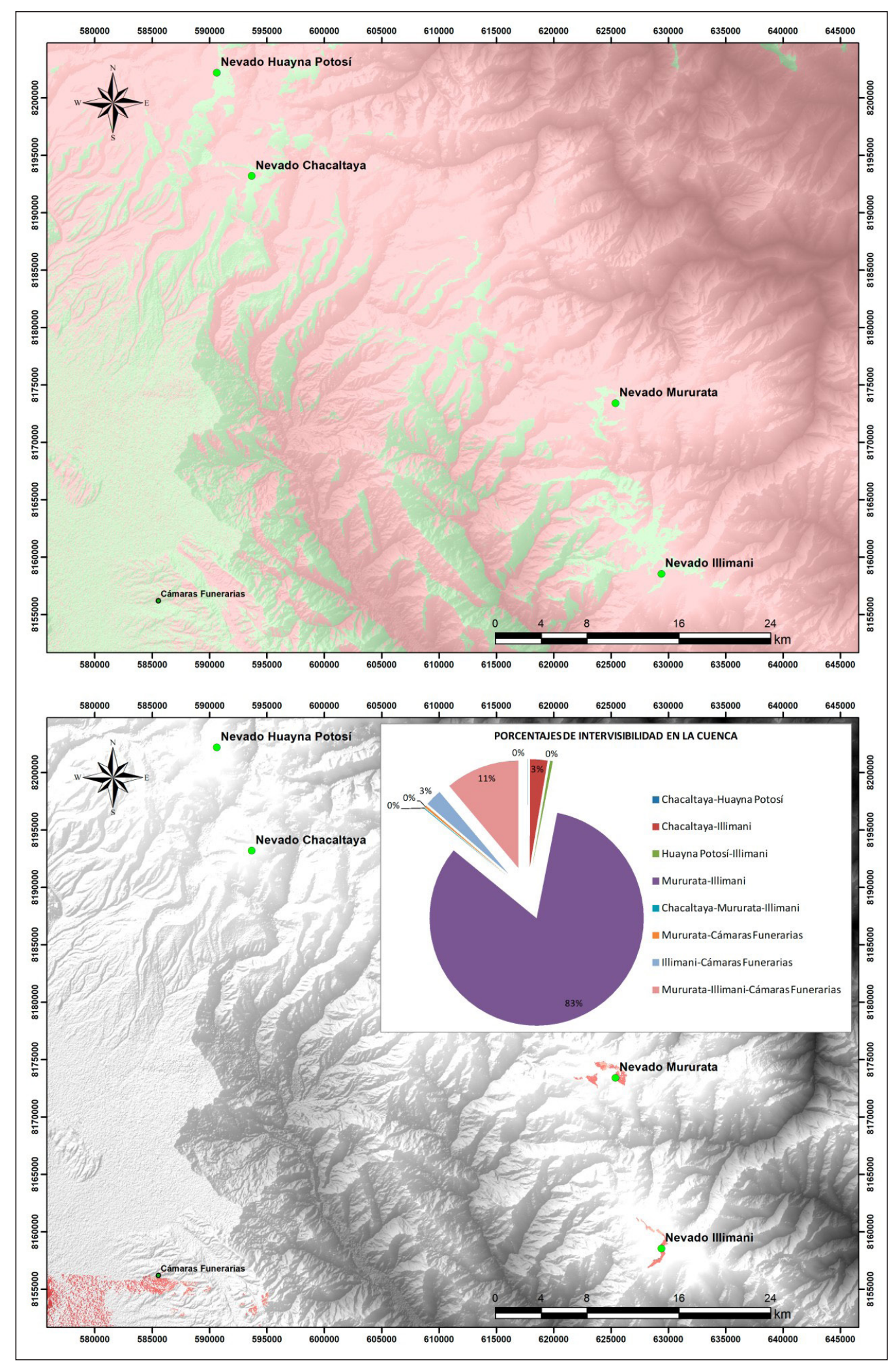

Elaboración propia 
Ambos análisis señalan una marcada reiteración visual relacionada a los nevados Illimani y Mururata. Esta reiteración cobra relevancia cuando abordamos a ambos nevados, importantes componentes del paisaje, desde la óptica del conocimiento acumulado y generado/recuperado alrededor de ambos. En primera instancia, recordemos que varios cronistas de inicios de la Colonia han subrayado la devoción de los Inkas por las cumbres nevadas, y su predilección en la ejecución de los ritos sacrificiales de la capacocha y la ubicación de santuarios de altura. En la actualidad, a decir de Reinhard:

Illimani ha tenido un papel tan dominante en las creencias religiosas tradicionales que se ha encontrado asociada a montañas tan distantes como la Tata Sabaya, a unos $300 \mathrm{~km}$ hacia el sur. Era la montaña sagrada referida en 1586 como una de las deidades mas adoradas en esta área [Cabeza de Vaca, 1965, p. 346; v. Calancha, 1974: 1960]. Eso no debería ser ninguna sorpresa porque, con una altura de $6.462 \mathrm{~m}$, es la montaña más alta entre el océano - al oeste - y la cuenca del Amazonas - al este (2012, p. 65).

De hecho, a guisa de ejemplo, se ha propuesto que el Illimani forma parte de los principales elementos que componen la cosmología de Tiwanaku (Vranich, 2006), los pobladores actuales de la isla del sol consideran al Illimani, junto al Illampu, un dios eterno y dueño de la tierra, que debe ser invocado en rituales para la lluvia ( $c f$. Schobinger, 1999; Ceruti y Reinhard, 2010), y los pobladores de Huancané (Perú) lo citan en sus ceremonias de ofrecimiento a la Pachamama. ${ }^{16}$

El mismo autor es muy claro al señalar que «fue el concepto de fertilidad, con el agua como su principal elemento, que ha sido encontrado subyacente en la vasta mayoría de las creencias relativas a las montañas», y prosigue afirmando que:

las deidades de las montañas eran vistas como esenciales para la fertilidad de los animales y campos, y fue principalmente en su condición de controladoras de fenómenos meteorológicos, que se ganaron una posición tan importante en la religión andina. Tales creencias claramente anteceden a los Incas, y han sido encontradas a lo largo de los Andes. Están basadas en hechos ecológicos básicos: lluvia, nubes y rayos, muchas veces se originan en las montañas, y los ríos descienden de ellas. Cuando los Incas entraron en áreas donde éstas creencias ya existían, aparentemente consideraron necesaria la construcción de sitios rituales, para ayudar a conseguir lo que era, en efecto, mayor control (político, religioso y

16. Valencia cita el siguiente discurso: «iLisiñsanakamanpi! (con vuestro permiso o licencia), santa tierra Pachamama, tus hijos nos hemos reunido para agradecerte por todos los frutos que nos has dado durante el año anterior y queremos renovar nuestra alianza contigo, ofreciéndote lo que te corresponde, lo que te gusta, y junto a ello nuestra vida, que es tu vida. jApu Pokopaka, Apu Santa Bárbara, Apu Chunkara, Apu Palomani, Apu Illimani [cursivas nuestras], Apu Awsangate!, esta noche en que ustedes se disponen para acoger todas las ofrendas del pueblo aymara, les queremos dar gracias por su constante protección, fuerza y sabiduría. ¡Uywirinaka! (guardianes o vigilantes), ¡kunturmamani! (cóndores y halcones), cuídennos esta noche de los espíritus malignos (supayanakata), aléjenlos de estos lugares para que no perturben nuestro agradecimiento a Dios». (1998, p. 48) 
económico) sobre la gente y la tierra que habían conquistado». (Reinhard, 1985, p.314; traducción propia).

De hecho, se ha detectado cierto continuum relacionado con el culto y significación de las montañas, reflejado en algunos rezos que Albó y Layme (1992) recopilan, como parte de la literatura oral aymara en la región. En estos, es común referirse al nevado Illimani como el «Abuelo», desde una óptica de cercano parentesco con el oficiante, pidiéndole que provea abundancia y haciendo énfasis en su riqueza, misma que comparte con aquellos que le ofrenden, principalmente si la ofrenda es acompañada de libaciones (reafirmando un fuerte lazo simbólico entre el nevado y lo líquido). Una situación análoga se genera en los ritos de veneración al Apu Qoylluriti, en el centro mismo de los rituales cusqueños (Duviols, 1986), en los que la peregrinación a la montaña sagrada involucra actividades relacionadas con la adoración a puquios (reservorios subterráneos de agua, de origen antrópico) y el traslado de bloques de hielo del nevado hacia los poblados, representando la distribución del agua desde tiempos inmemoriales.

En cuanto a los nevados bolivianos, el recopilador Antonio Paredes Candia parece ser la mejor fuente, ya que su monumental obra ha incursionado en todos los aspectos relacionados con los mitos, leyendas y cuentos folclóricos de la zona andina de Bolivia. Una de sus mejores referencias a los nevados Illimani y Mururata y probablemente la más conocida entre los mitólogos y mitógrafos, procede de una leyenda en la que el segundo reta al primero a una contienda, resultando en su decapitación mediante un hondazo, acto que explicaría su plana cima y su nombre (Paredes, 1979, pp.190191). Son pocas y escuetas las fuentes que refieren al nevado Mururata (v. gr. Ibid., Paredes,1968; Jemio (coord.) 2011; Moscoso, 2000; Ribera, 2019; Romero, 2000, p.62); sin embargo, se lo reseña como el castigador, que porta vientos, nieve y granizo, en dualidad y complementariedad contrapuesta al Illimani (junto al cual es retratado siempre, como un ente de menor categoría, pero igual importancia).

\section{Etnoarqueología iconográfica}

Siendo tan evidente la relevancia de ambos nevados en regiones tan distantes del altiplano, se puede suponer que el Illimani y el Mururata constituyen un pivote elemental del cosmos en su región inmediata. De hecho, las referencias recuperadas por los autores, anteriormente citados, afirman que el culto a estos Apus (principalmente el primero de ellos) se halla vigente hasta nuestros días, por lo que no deberá sorprender al investigador que los pobladores de la comunidad de Chacoma (el asentamiento humano más cercano al yacimiento de Mazocruz) así lo refieran.

Sin embargo, las referencias orales a este culto constituyen solamente una parte del constructo de evidencia en las que se apoya este análisis. Otra parte está compuesta por la evidencia material que los pobladores han generado, como reflejo de la compleja red de significados y conceptos que aluden al culto. En el caso de los pobladores de 
Chacoma, una práctica es determinante para la comprensión del continuum histórico en el culto al nevado: las representaciones iconográficas (eróticas) y los textos que las acompañan, plasmadas en la superficie visible (Porciones norte y sur) de la roca puzolana (Figura 5).

Las áreas marcadas del afloramiento revisten una importancia doble a nivel ceremonial, siendo especialmente llamativo el hecho de que posean una vista clara y directa hacia el Illimani (Figura 6) y el Mururata, y su correlación espacial con actividades ceremoniales funerarias de la época prehispánica (pues es en el área sur, en su extremo oeste, que se reportó el hallazgo de las tumbas).

Como se señalaba en líneas anteriores, se ha detectado que durante la época moderna se ha elaborado una serie serie de representaciones, que podrían calificarse como «rupestres», ordenadas en tres grupos: a) antropomorfas (formas sexuadas, principalmente con presencia de vulvas), b) textuales (nombres de parejas, con un componente masculino y uno femenino), c) artísticas (tallados) (Figura 7). En el caso de los tallados, fueron aprovechadas las formas naturales del afloramiento para elaborar una serie de desgastes y rebajes que conforman estructuras ordenadas; las formas sexuadas y los textos de nombres emparejados se presentan siempre acompañados, expresando una clara asociación.

Figura 5. Áreas de Representaciones Iconográficas (Rupestres) eróticas en el yacimiento

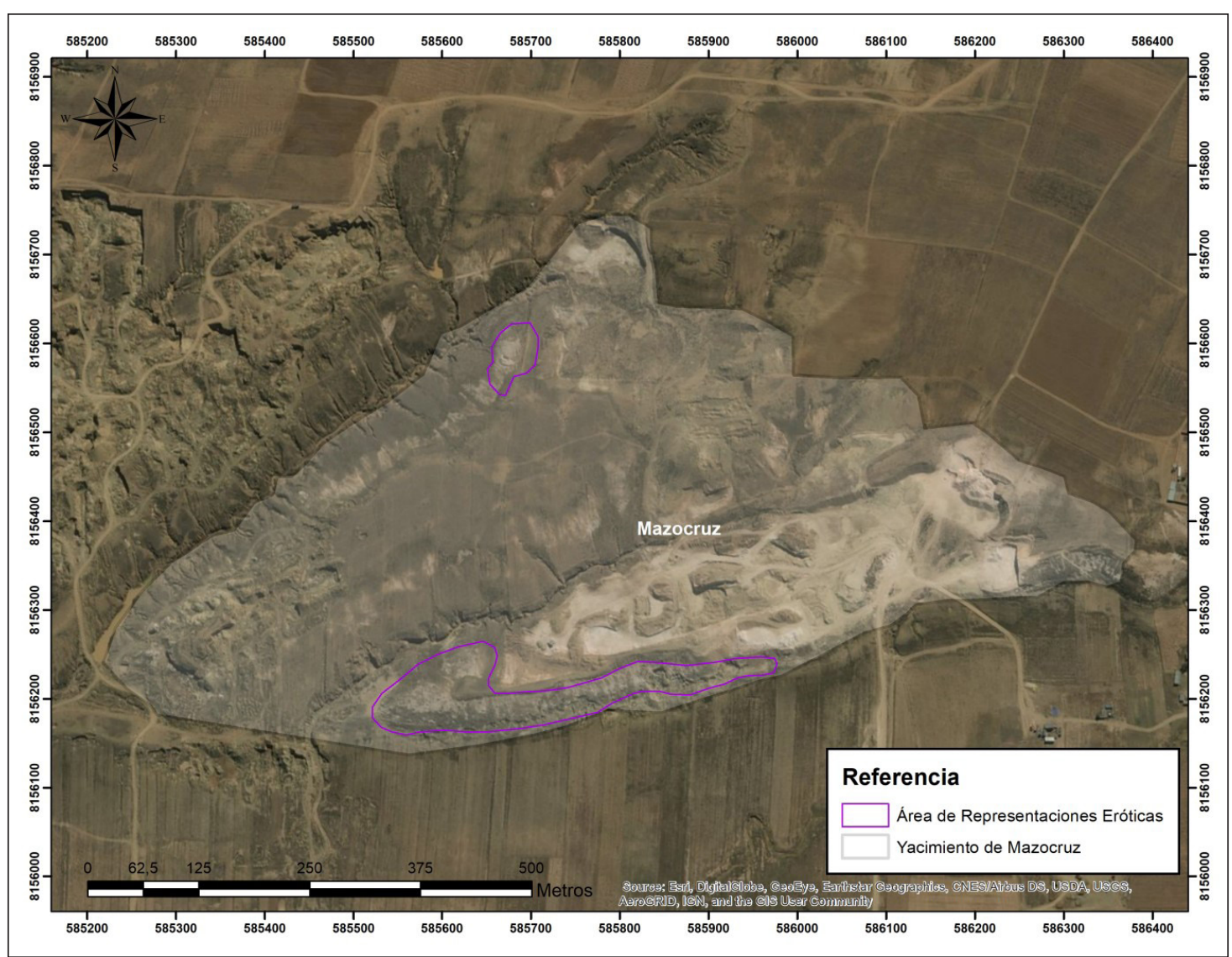

Elaboración propia 
Figura 6. Vistas del Illimani (centro al fondo) desde las áreas de representaciones eróticas.
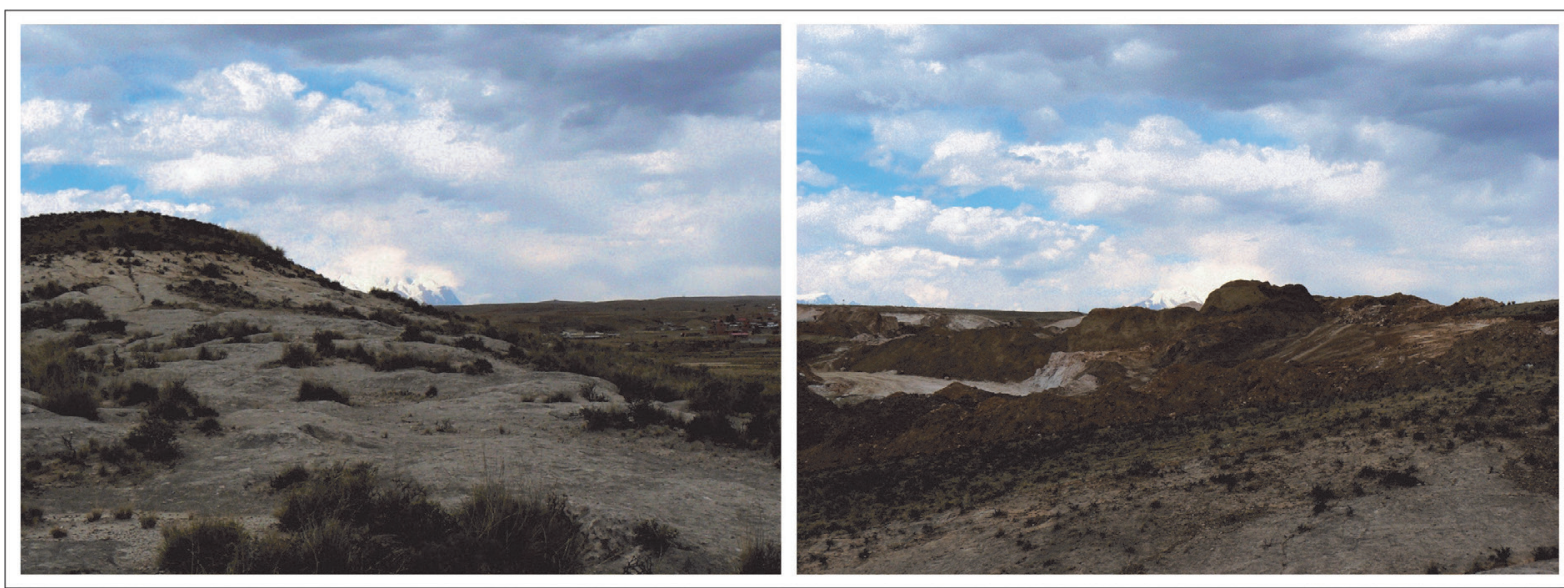

Elaboración propia

A pesar de lo anterior, aún se hace necesaria una etnografía de las poblaciones circundantes que indague sobre el fenómeno de estas representaciones y sus significados para los pobladores locales, pues lo observado hasta aquí responde a una interpretación de la interrelación de elementos de juicio y análisis, y una documentación detallada de los motivos y textos. Así también, esta etnografía debe enfatizar en su ubicación, posición, rango visual, e indagar en las actividades de las que son resultado, además de las actividades en las que se ven involucradas y los ciclos de uso y desuso (en relación con otros ciclos como el agrícola) a los que las representaciones son sometidas.

Figura 7. Figura femenina, tallados y vulva

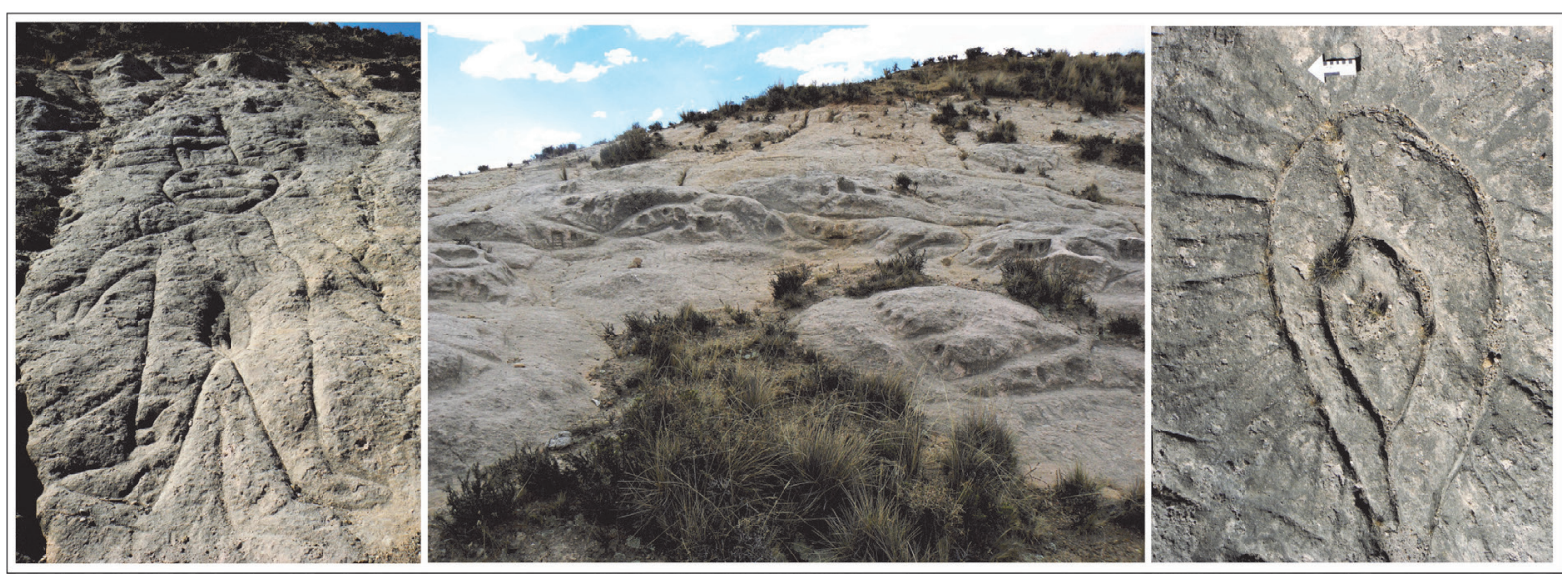

Elaboración propia 


\section{Un probable porqué de Mazocruz en tiempos prehispánicos}

Al haber presentado variaslíneas de evidencia que apuntalan un probable significado del yacimiento, para el momento de los enterramientos prehispánicos, se ha puesto en evidencia la interrelación del mismo con el paisaje, principalmente montañoso, circundante. Este diálogo de significantes geográficos, como eminencias o anomalías dentro de la planicie altiplánica, se hallaría indiscutiblemente relacionado con los principios estructurales de la cosmovisión andina.

Ello nos lleva a afirmar que en un culto religioso helio-centrista, como tópico predominante en la religión popular nativa, la coincidencia astronómicogeográfica que viene dada por el direccionamiento de los principales rasgos geográficos - tendiente siempre al este - y el alineamiento de las montañas con el sol, en levante, genera que las creencias relativas al ciclo mítico y a los significados y significantes que este contiene, se vea aún más reforzada en un horizonte visual muy probablemente sagrado (en el que el Illimani y el Mururata son los principales actores).

Por todo lo anteriormente expuesto, proponemos que Mazocruz, durante el Intermedio Tardío y el Horizonte Tardío, constituyó una wak̉a local de gran importancia, cuya ligazón cosmológica se halla relacionada con el Apu Achachila Illimani (la montaña tutelar más importante de la región inmediata) y el Apu Mururata (segundo en importancia). En ese sentido, podríamos asegurar que los cuerpos depositados en los enterramientos del yacimiento tuvieron los rostros direccionados hacia estos Apus. Esta importancia se habría visto vedada durante la Colonia, probablemente debido al proceso de extirpación de idolatrías que afectó, de igual forma, a otras tantas wak'as en los Andes (bien invisibilizándolas para protegerlas, o bien exorcizándolas si su uso era verificado). ${ }^{17}$

Sin embargo, así como el tiempo es cíclico en la cosmovisión andina, y los procesos culturales tienden a regresar a ciertos principios que reflejan continuidades, esta wak'a perdida habría recobrado parte de su significado mediante el uso actual - posiblemente erótico, reproductivo- que las comunidades cercanas hacen de ella, plasmando motivos, íconos y escritura relacionadas al emparejamiento y la sexualidad (cuyo ciclo es de importancia capital para cualquier grupo humano) en la superficie de la tierra (iniciadora de vida en el mundo andino) que tiene una vista directa al «dador de vida» Apu Illimani y a su par dual el Apu Mururata, los cuales se encuentran cerca a los ingresos de las tumbas, manifestando que los espacios en los que convergen tanto la muerte como la vida, siempre se relacionan con la idea de fecundidad que proviene de los entes tutelares que pueblan el paisaje andino.

17. Un ejemplo, desarrollado desde otra óptica, puede verse en Méncias (2009). 
El culto a los Apus y la Pachamama, aunque teñido de inferencias religiosas modernas e impuestas, sigue vivo, ahora mismo, entre las poblaciones que ocupan y viven en el paisaje andino. Los pagos y ofrendas mediante hojas de coca, alcohol y mesas dulces continúan siendo una práctica común, en la búsqueda de las dádivas de los espíritus tutelares, así como sigue siendo común la noción de que la vida inicia y termina en la tierra, en la que se cumple un ciclo ininterrumpido de renacimientos. (Marzal, 2005; Albó, 2005).

Aún falta mucho para definir las características y particularidades de los sujetos inhumados en Mazocruz, principalmente debido a la ausencia casi total de material orgánico humano que pudiera permitir análisis de isótopos estables o secuencias de ADN mitocondrial. Sin embargo, se puede proponer que una de las razones de haber ejecutado un proceso de inhumación tan anómalo, en comparación con el patrón conocido para ambos períodos, considerando incluso la fuerte inversión de técnica y tecnología necesarias para construir las cámaras subterráneas (en un soporte tan delicado como la puzolana), es que los individuos inhumados se hallarían relacionados a poderosos procesos y fenómenos correlacionados con la Religión Popular Nativa (en sus principios más elementales e invariables), según las interpretaciones en líneas anteriores. Por lo tanto, también se refuerza la creencia de que los Apus más relevantes de su entorno velarían por su eterno descanso en la otra vida, durante un ciclo inquebrantable de renacimientos que inician con la tierra y el agua de las montañas, y terminan en el territorio de la comunidad (alimentado por ellas). ¿Acaso es Mazocruz el último descanso de malqui venerados y olvidados? Solo mayores, y más sistemáticas investigaciones nos acercarán a una probable respuesta. 


\section{Referencias}

Albó, X. (2005). Religión aymara. En M. Marzal (Ed.), Enciclopedia Iberoamericana de Religiones. Religiones Andinas (Vol. 04, pp. 175-200). Madrid: Editorial Trotta.

Albó, X., y Layme, F. (1992). Literatura Aymara Antología. I. Prosa. La Paz: CIPCA hisbol - JAYMA.

Berrojalbiz, F. (Ed.). (2015). La vitalidad de las voces indígenas: arte rupestre del contacto $y$ en sociedades coloniales. México, D.F.: Universidad Nacional Autónoma de México, Instituto de Investigaciones Estéticas.

Bertonio, L. (1984 [1612]). Vocabulario de la Lengua Aymara. La Paz: CERES, IFEA, MUSEF.

Betanzos, J. d. (2004). Suma y narración de los Incas. (M. d. Martín Rubio, Ed.) Madrid: Editorial Polifemo.

Bouysse-Cassagne, T. (1987). La Identidad Aymara. Aproximación histórica (Siglo XV, Siglo XVI). La Paz: Hisbol, IFEA.

Bouysse-Cassagne, T., y Bouysse, P. (1986). Volcan indien, volcan chrétien. À propos de l>éruption du Huaynaputina en lıan 1600 (Pérou méridional). Journal de la Société des Américanistes, LXX, 43-65.

Bouysse-Cassagne, T., y Bouysse, P. (1988). Lluvias y Cenizas, Dos Pachacuti en la historia. La Paz: HISBOL.

Bradford, J. (1957). Ancient Landscapes. Studies in field Archaeology. Londres: G. Bell and Sons, Ltd.

Bray, T. (Ed.). (2015). The archaeology of wak'as: explorations of the sacred in the preColumbian Andes. Boulder: University Press of Colorado.

Brosseder, C. (5 de Septiembre de 2014). El alcance de los poderes de "huacas" y de "camascas" en los Andes. doi:10.4000/nuevomundo.67115

Burucúa, J., Siracusano, G., y Jáuregui, A. (1999). Colores en los Andes: sacralidades prehispánicas y cristianas. (L. Enriquez, Ed.) (In)disciplinas: estética e historia del arte en el cruce de los discursos (XXII Coloquio Internacional de Historia del Arte).

Centro de Culturas Originarias Kawsay. (2005). Metodología Propia, Educación Diferente. Cochabamba: Editorial Kipus.

Ceruti, M., y Reinhard, J. (2010). Inca Rituals and Sacred Mountains: A Study of the World's Highest Archaeological Sites. Los Ángeles: UCLA (Cotsen Institute of Archaeology).

Chase, Z. (2015). What is a Wak'a? When is a Wak'a? En The Archaeology of Wak'as: Explorations of the Sacred in the Pre-Columbian Andes (pp. 75-126). Boulder: University Press of Colorado.

Colque, G. (2009). Autonomías indígenas en tierras altas. Breve mapeo para la implementación de la Autonomía Indigena Originaria Campesina. La Paz: Fundación Tierra. 
Cruz, P. (2009). Huacas olvidadas y cerros santos. Apuntes metodológicos sobre la cartografía sagrada en los Andes del sur de Bolivia. Estudios Atacameños(38), 55-74.

Cruz, P., Crubézy, E., y Gérard, P. (2013). Los Adoratorios de Altura Inkaicos. Una mirada desde el cerro Cuzco, departamento de Potosí, Bolivia. Memoria Americana, 21(1), 93120 .

di Salvia, D. (2013). La Pachamama en la época incaica y post-incaica: una visión andina a partir de las crónicas peruanas coloniales (siglos XVI y XVII). Revista Española de Antropología Americana, 43(1), 89-110.

Dillehay, T. (Ed.). (1995). Tombs for the Livinng: Andean Mortuary Practices. Washington, D.C.: Dumbarton Oaks.

Donnan, C. (1995). Moche funerary Practice. En T. Dillehay (Ed.), Tombs for the Livinng: Andean Mortuary Practices (pp. 111-160). Washington, D.C.: Dumbarton Oaks.

English, P., y Mayfield, R. (Edits.). (1972). Man, Space, and Environment: Concepts in Contemporary Human Geography. New York: Oxford University Press.

Gentile, M. (2018). Vulcanismo y terremotos andinos. Alcance sociopolítico y religioso de algunas creencias en el siglo XVI. Anuario Jurídico y Económico Escurialense, LI, 569-588.

Gil, F. (2001). Ideología, poder y territorio. Por un análisis del fenómeno chullpario desde la Arqueología de la Percepción. Revista Española de Antropología Americana(31), 59-96.

Gil, F. (2002). Acontecimientos y regularidades chullparias: más allá de las tipologías. Reflexiones en torno a la construcción del paisaje chullpario. Revista Española de Antropología Americana(32), 207-241.

Gil, F., y Fernández, G. (2008). El culto a los cerros en el mundo andino: estudios de caso. Revista Española de Antropología Americana, 38(1), 105-113.

González Holguín, D. (1952 [1608]). Vocabvlario dela lengva general de todo el Perv llamada lengua Qquichua o del Inca. (R. Porras Barrenechea, Ed.) Lima: Universidad Nacional Mayor de San Marcos.

González, R. (2006). Una disciplina denominada Arqueología del Paisaje. Apuntes de Ciencia y Tecnología(20), 28-36.

Haverkort, B. (2001). COMPAS: Apoyando el desarrollo endógeno. En J. Bilbao (Ed.), Cosmovisión Indígena y Biodiversidad en América Latina (pp. 7-26). Cochabamba: COMPAS, AGRUCO.

Kaulicke, P. (1994). Los orígenes de la civilización Andina: Arqueología del Perú. En J. A. Del Busto (Ed.), Historia General del Perú (Vol. 1). Lima: Editorial Brasa.

Kaulicke, P. (1997). La Muerte en el Antiguo Perú. Contextos y conceptos funerarios: una introducción. Boletín de Arqueología PUCP, 1, 7-54.

Kaulicke, P. (2018). Conceptos incaicos de vida, muerte y culto a los ancestros. En I. Shimada (Ed.), El Imperio Inka (pp. 407-428). Lima: Pontificia Universidad Católica del Perú. 
Kesseli, R., y Martti, P. (2005). Identidad étnica y muerte: torres funerarias (chullpas) como símbolos de poder étnico en el altiplano boliviano de Pakasa (1250-1600 d. C.). Bulletin de l'Institut Français d'Études Andines, 34(3), 379-410.

Kosiba, S. (2015). Ofblood and soil: Tombs, wak'as, and the naturalization of social difference in the inka heartland. En T. Bray (Ed.), The Archaeology of Wakas: Explorations of the Sacred in the Pre-Columbian Andes (pp. 167-212). Boulder: University Press of Colorado.

Kusch, R. (1970). El Pensamiento Indígena Americano. Puebla: J.M. Cajica.

Larco, R. (1941). Los Cupisniques. Trabajo presentado al Congreso Internacional de Americanistas de Lima, XXVIII, Sesión, La Crónica y Variedades, Lima.

Leveau, P. (2005). L’archéologie du paysage et l’antiquité classique. Agri centuriati an International Journal of Landscape Archaeology(2), 9-24.

Llobera, M. (2003). Extending GIS-based visual analysis: the concept of visualscapes. International Journal of Geographical Information Science, 17(1), 25-48.

Llobera, M. (2018). Visibility Modeling. En S. López Varela, y J. Thomas (Edits.), Encyclopedia of Archaeological Sciences (pp. 1-3). Hoboken: John Wiley y Sons Ltd.

Martín, M. (2009). La cosmovisión religiosa andina y el rito de la Capacocha. Investigaciones Sociales, 13(23), 187-201.

Marzal, M. (2005). La religión quechua actual. En M. Marzal (Ed.), Enciclopedia Iberoamericana de Religiones. Religiones Andinas (Vol. 04, pp. 143-174). Madrid: Editorial Trotta.

Medinacelli, X. (Ed.). (2012). Turco Marka. Hombres, Dioses y Paisaje en la historia de un pueblo orureño. La Paz: Universidad Mayor de San Andrés, Instituto de Estudios Bolivianos, Fundación Cultural del Banco Central de Bolivia.

Méncias, J. (2009). Huacas sagradas y el proceso de extirpación de idolatrías: el caso de la iglesia de San Sebastián visto desde la cerámica. Khana, Revista Municipal de Culturas, número especial del Bicentenario de la Revolución de 1809(50), 43-53.

Méncias, J. (2018). Arqueología Rupestre en el complejo arqueológico de Pumiri (Provincia Sajama del Departamento de Oruro, Bolivia). Tesis inédita para optar al grado de Licenciatura en Arqueología en la Universidad Mayor de San Andrés, Facultad de Ciencias Sociales. La Paz: Carreras de Antropología-Arqueología.

Onuki, Y. (1995). Kuntur Wasi y Cerro Blanco. Dos sitios del Formativo en el norte del Perú. Tokio: Hokusen-sha.

Onuki, Y. (1997). Ocho tumbas especiales de Kuntur Wasi. Boletín de Arqueología PUCP, $1,79-114$.

Querejazu, R. (1994). Religiosidad popular andina y su relación con el arte rupestre en Bolivia. Yachay, 10(18), 121-139.

Querejazu, R. (1996). Impacto Hispano-Indígena en Charcas. Análisis Histórico del Coloniaje. La Paz: Librería Editorial Juventud. 
Reinhard, J. (1985). Sacred Mountains: an Ethnoarchaeological Study of High Andean Ruins. Mountain Research and Development, 5(4), 299-317.

Reinhard, J. (2012). Las Montañas Sagradas y las Culturas Preincaicas de los Andes. En M. Chávez y Peniche, S. Iwaniszewski, y R. Cabrera (Edits.), América: Tierras de Montañas $y$ Volcanes. Huellas de la Arqueología (pp. 51-71). México, D.F.: Instituto Nacional de Antropología y Historia (INAH).

Rozas, C. (2012). «Chullpas» Historia del concepto, antecedentes, definiciones, autores involucrados y lugares estudiados. Quito: Universidad Internacional SEK. Facultad de Estudios del Patrimonio Cultural.

Sagárnaga, J. (2006). Chullpas y Chullpares: Maravillas Funerarias Precolombinas. Conferencia presentada en el Segundo Encuentro de Valoración y Gestión de Cementerios Patrimoniales, La Paz.

Salazar, A. (2001). Estudio y transformación de puzolanas naturales en productos de alta actividad para uso en la industria de la construcción. Desarrollo de productos y aplicaciones diversas en ECOMAT S.A. (Proyecto de Investigación y Desarrollo).

Schobinger, J. (1999). Los Santuarios de Altura Incaicos y el Aconcagua: Aspectos generales e interpretativos. Relaciones de la Sociedad Argentina de Antropología, XXIV, 7-27.

Siracusano, G. (2005). El Poder de los Colores. De lo material a lo simbólico en las prácticas culturales andinas (siglos XVI-XVIII). Buenos Aires: Fondo de Cultura Económica de Argentina, S.A.

Star, J., y Estes, J. (1990). Geographical Information Systems: An Introduction. Englewoods Cliffs, New Jersey: Prentice Hall.

Steele, P., y Allen, C. (2004). Handbook of Inca Mythology. Santa Bárbara, California: ABC-CLIO.

Tantaleán, H. (2006). Regresar para construir: Prácticas Funerarias e Ideología(s) durante la ocupación Inka en Cutimbo. Chungará, Revista de Antropología Chilena, 38(1), 129-143.

Tévar, G. (1996). La Cuenca Visual en el Análisis del Paisaje. Serie Geográfica(6), 99-113.

Ulloa, J. d. (1889 [1583]). Relación de la provincia de los Collaguas para la discrepcion de las Yndias que Su Magestad manda hacer. Indios de la Corona real de Su Magestad. En Relaciones Geográficas de Indias (Vol. II, pp. 38-50). Madrid.

Valencia, F. (1987). Introducción a la Geografía Física. México, D.F.: Ed. Herrero.

Valencia, N. (1999). La Pachamama: Revelación del Dios creador. Quito: Ediciones ABYAYALA, Insituto de Estudios Aymaras.

van Kessel, J. (1990). Tecnología aymara: Un enfoque cultural. En J. Earls, E. Grillo, H. Araujo, y J. van Kessel, Tecnología Andina. Una introducción (pp. 143-226). La Paz: HISBOL.

Vranich, A. (2006). The Construction and Reconstruction of Ritual Space at Tiwanaku, Bolivia (A.D. 500-1000). Journal of Field Archaeology(3), 121-136. 